\title{
Téoros
}

Revue de recherche en tourisme

\section{Région touristique de Charlevoix}

\section{Valérie Théberge}

Volume 17, numéro 1, printemps 1998

Le tourisme dans un Pays à part : Charlevoix

URI : https://id.erudit.org/iderudit/1072383ar

DOI : https://doi.org/10.7202/1072383ar

Aller au sommaire du numéro

Éditeur(s)

Université du Québec à Montréal

\section{ISSN}

0712-8657 (imprimé)

1923-2705 (numérique)

Découvrir la revue

\section{Citer ce document}

Théberge, V. (1998). Région touristique de Charlevoix. Téoros, 17(1), 64-64. https://doi.org/10.7202/1072383ar d'utilisation que vous pouvez consulter en ligne.

https://apropos.erudit.org/fr/usagers/politique-dutilisation/ 
Valérie Théberge, bibliothécaire Centre de documentation touristique UQAM-ACTA

\section{MONOGRAPHIES}

Association touristique régionale de Charlevoix (1997), La région touristique de Charlevoix: l'état de situation. les défis, les enjeux, La Malbaie, Association touristique régionale de Charlevoix. Disponible à TOURISME QUÉBEC

DES GAGNIERS, Jean (1994), Charlevoix, pays enchanté, Sainte-Foy, Presses de I'Université Laval.

Disponible à l'UQAM

DUBÉ, Philippe et Jacques BLOUIN (1986), Deux cents ans de villegiature dans Charlevoix: I'histoire du pays visite, Sainte-Foy,

Presses de I'Université Laval.

Disponible au Centre de documentation en tourisme

DUBE, Richard et François TREMBLAY (1989), Peindre un pays: Charlevoix et ses peintres populaires, LaPrairie, M. Broquet.

Disponible à I'UQAM

DUMAS, Alain et Yres OUELLET (1997), Charlevoix: joyau du Québec. Saint-Laurent, Trécarré.

Disponible à I'UQAC

FILLION, Jean (1994), La mise en valeur récréo-touristique du comté de Montmorency, Québec, l'auteur. Disponible à TOURISME QUÉBEC

GROUPE ARKOS (1989), Exposé de projet: pavillon de la réserve mondiale de la biosphère de Charlevoix, S.L., Groupe Arkos

Disponible à TOURISME QUÉBEC

L'ÉCART-TYPE (1992), Étude de marché du parc marin du Saguenay. S.L., L'Écart-type. Disponible à TOURISME QUÉBEC

MIA et KLAUS et Cyril SIMARD (1994), Charlevoix, Montréal.

Editions de I'Homme.

Disponible à I'UQAM

\section{THËSES}

GUÉRIN, Michel (1990), Peuplement et dynamique démographique de Charlevoix des origines a aujourd'hui, Sainte-Foy, Université du Québec.

Disponible à I'UQAM

SIMARD, Cyril (1986),

L'économuséologie :

essai d'ethnologie appliquée, these

de doctorat, Université Laval.

Disponible à l'UQAM

THIBAULT, Jean-Pierre (1991). La planification touristique:

la relation entre son elaboration et sa mise en oeuvre, mémoire de maîtrise. Université du Québec à Rimouski.

Disponible à I'UQAR

\section{AUTRES}

BDG Communications et Société d'histoire de Charlevoix (1996), Les pays de Charlevoix, l'arrière pays : guide audio touristique, Montréal, BDG Communications.

\section{SITES WEB}

http://www.freeway.net/community/ charlevoix

http://www.quebecweb.com/tourisme/ charlevoix

http://www.st-joseph-de-la-rive.qc.ca

Merci, Marc...

Lors de sa retraite de I'UOAM, àl'été 1996. Mare Laplante a propose - et nous lui en sûmes gré - de conserver bénévolement ses fonctions de rédacteur en chef de Téoros, une revue de recherche en tourisme qui lui tient à coeur et qu'il a contribue a faire naitre en $1982-$ scize ans dejà

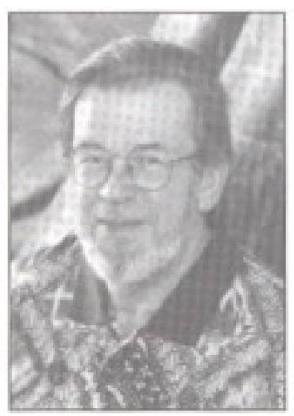

Depuis plusieurs annęes, alternativement comme directeur et rédacteur en chef. Marc Laplante a fait grandir la revue par son travail d'animateur, par ses propositions originales, par ses exigences de qualité... par sa passion. Récemment, avec I'aide du comité de direction el de redaction. il a revu la politięue éditoriale de Téoros et amoré certains changements dont celui de soumettre quelques articles à l'appréciation d'évaluateurs externes, répondant ainsi aux exigences des revues savantes tout en maintenaint la fonction de trait d'union qu' assume Téoros entre le monde de la recherche et le secteur professionnel du tourisme.

Dorénavant, explorant de nouvelles avenues que lui entrouve la retraite, Mare ne souhaite plus exercer de responsabilites importantes au sein de Téoros tout en acceptant de continuer à sięger au comité dé direction el de rédaction.
Au nom du comité et en mon nom personnel. je le remercie sineèrement pour son dévouement et jespềre pouvoir compter longtemps sur sa culture... et sil passion créalrice.

A compter du prochain numéro, madame Lucie $\mathrm{K}$. Morisset, professeure au département d'études urbaines et touristiques de I'UQAM et chercheure au CELAT, prendra la releve de Mare comme rédactrice en chef. À l'ete 1997, madame Morisset a réalisê avec brio la coordination thématique du numero ayant pour theme aTourisme et religions: et je lui suis reconnaissant d'avoir répondu à notre appel.

... d'autres remerciements aux collaborateurs Quelques collaborateurs de longue date se sont retirés du comité de direction et de rédaction ces derniers mois parce que leurs responsabilités actuelles ou de nouveaux engagements ne leur permettaient plus d'assurer une présence soutenuc au comité. Je remercie de lout oncur pour leur contribution fructueuse, à divers titres, madame Sylvic Gagnon et messieurs Pierre Bellerose et Michel Zins. lls sont remplacés par madame Suzanne Chasse. professeure en tourisme au Cégep de Granby, monsieur Laurent Bourdeau, professeur de marketing à I'Université Laval et monsieur François Bédard, professeur au département d'études urbaines et touristiques de I"UQAM. A ces derniers, bienvenue et merci à l'avance.

Louis Jolin, directeur de Téoros 